\title{
Diagnosis of American Cutaneous Leishmaniasis by Enzyme Immunoassay in Patients from Northern Paraná State, Brazil
}

Kelly Aparecida Geraldo Yoneyama, Leyde Daiane de Peder, Maria Valdrinez Campana Lonardoni, Thaís Gomes Verzignassi Silveira State University of Maringá, Department of Clinical Analysis; Maringá, PR, Brazil

\begin{abstract}
American cutaneous leishmaniasis (ACL) is an endemic disease caused by Leishmania parasites. The ACL diagnosis is commonly accomplished by parasitological and immunological methods. The objective of this work was to evaluate the enzyme immunoassay (EIA) for ACL laboratorial diagnosis. IgG antibodies against Leishmania (Viannia) braziliensis promastigotes were researched. For the method standardization 240 sera were used: 72 from patients with positive parasitological diagnosis, 38 from normal individuals and 113 from individuals with other pathologies. The sensibility was $93 \%$ and the specificity was $70 \%$. Regarding diagnosis, EIA showed $97 \%$ positivity in patients with ACL and $97 \%$ negativity in patients with other cutaneous lesions. The EIA presented a good performance when used for diagnosis, thus, it may become an important tool for it and for further ACL epidemiological studies in endemic areas.
\end{abstract}

Key-Words: Cutaneous leishmaniasis, diagnosis, antibodies, immunoenzyme, Leishmania braziliensis.

Leishmaniasis is a wide spectrum disease transmitted by phlebotomine sandflies infected with Leishmania parasites. The disease can be manifested in cutaneous, mucocutaneous or visceral forms, depending on the parasite characteristics and the immune system of the host. According to the World Health Organization, leishmaniasis attacks more than 12 million people in the world, with an annual incidence of 1.5 million [1]. The most common form of the disease is the cutaneous one, with estimated 1.5 million new cases per year worldwide [2]. American cutaneous leishmaniasis (ACL) occurs from southern Texas to northern Argentina mainly in rural areas. Cutaneous leishmaniasis in Latin America is associated with mucocutaneous leishmaniasis, a chronic destructive condition that is difficult to be treated. ACL is reported in all of Brazil's states and it is an endemic disease mainly in the north and west of Paraná State [3-6], where the causative agent Leishmania (Viannia) braziliensis was isolated from dogs [7], humans [5] and sandflies [8].

The laboratorial diagnosis of ACL is carried out by parasitological and immunological tests. Parasites must be demonstrated in infected tissue for confirmatory diagnosis. Therefore, the success of the parasite search depends on the time of lesion evolution [9]. Montenegro's skin test (MST), which is very simple and highly sensitive, lacks specificity, and can not distinguish between active, inactive or past infection $[9,10]$. Several DNA primers exist for Leishmania detection; however, they are not enough standardized for widespread use. Serological tests are rarely performed to diagnose cutaneous leishmaniasis. Among the serological tests used for the diagnosis are the direct agglutination,

Received on 10 February 2007; revised 9 May 2007.

Address for correspondence: Dr. T.G.V. Silveira. Laboratório de Ensino e Pesquisa em Análises Clínicas, Departamento de Análises Clínicas, Universidade Estadual de Maringá. Av. Colombo, 5.790. Zip code: 87.020-900 - Maringá - Paraná, Brazil. Supported by Fundação Araucária

The Brazilian Journal of Infectious Diseases

2007;11(3):360-364. (C) 2007 by The Brazilian Journal of Infectious Diseases and Contexto Publishing. All rights reserved. indirect immunofluorescence (IIF), and enzyme immunoassay (EIA). Some EIA techniques for the ACL diagnosis were described by several authors that used L. braziliensis [11-14] and other Leishmania species [15-17] as antigen, and they detected IgG [12, 14, 15, 17, 18], IgM [12] or IgA antibodies [13].

The association of different tests increases the positivity of the ACL laboratorial diagnosis. Studies accomplished at Maringá's State University Teaching and Research Clinical Analysis Laboratory (LEPAC/UEM) showed that, when the parasitological tests were associated with the IIF, the positivity was $84.3 \%$, and when the IIF was associated with the MST the positivity was $98.8 \%$ [5]. On the other hand, the serological methods are less invasive, and reports in the literature show that the antibodies' levels decrease with the clinical cure of ACL, not interfering in the retrospective diagnosis of the disease [9].

The aim of the present study was to evaluate the contribution of the enzyme immunoassay for ACL laboratorial diagnosis in patients from northern Paraná State, Brazil.

\section{Materials and Methods Serum Samples}

Seventy-two serum samples from ACL diagnosed patients were collected from the Teaching and Research in Clinical Analysis Laboratory of the State University of Maringá (LEPAC/UEM). These patients were from endemic areas, having ulcers suggestive of ACL, which were confirmed parasitologically: Leishmania sp. was detected in the ulcer by scratching the internal border of lesion and staining with Giemsa stain. These patients were also positive in Montenegro's skin test (MST) and indirect immunofluorescence IgG test (IIF-IgG). After diagnosis, all patients were treated with sodium antimony gluconate as recommended by the Ministry of Health regulations. The patients' mean age was 34.1 years, ranging from 5 to 71 . Thirty-eight serum samples from healthy individuals and without clinical history of ACL were used as healthy controls. One hundred and thirteen serum samples from patients with positive serology for other diseases were obtained from 
LEPAC/UEM. This serum group included 36 patients with toxoplasmosis (presence of IgG by enzyme immunoassay Abbott Laboratories), 15 patients with recent toxoplasmosis (presence of both IgG and IgM by enzyme immunoassay Abbott Laboratories), 36 patients with Chagas' disease (IgG positive by both IIF - BioMèrieux - and enzyme immunoassay - Abbott Laboratories), 14 patients with syphilis (positive FTA-ABS test - BioMèrieux), and 12 patients with paracoccidioidomycosis (positive immunodiffusion test) kindly provided by Dr. T. I. E. Svidzinski, LEPAC/UEM. The samples were stored at $-20^{\circ} \mathrm{C}$ until being used.

In this study, 76 patients with cutaneous ulcers and 9 patients with mucous ulcers, both groups suspicious of ACL, were also evaluated. The mean age of the patients with cutaneous ulcers was 37.5 years, ranging from 7 to 81 . Fiftyone patients were male and 25 female. The patients with mucous ulcers had a mean age of 56.7 years, ranging from 37 to 81 , and 6 were male and 3 female. Samples were collected after filling out participants " informed consent. This work was approved by Maringá's State University Ethical Committee, and was conducted according to the rules of the National Council of Health of the Health Ministry.

\section{Parasite and Antigens}

Leishmania (Viannia) braziliensis (MHOM/BR/1987/ M11272) were maintained in blood agar medium (Difco) containing $15 \%$ defibrinated rabbit blood at $25^{\circ} \mathrm{C}$. Mass cultivation of parasites was done in 199 medium (Sigma) supplemented by $0.2 \mathrm{mM} \mathrm{L}$-glutamine, $100 \mathrm{UI} / \mathrm{mL}$ penicillin $\mathrm{G}$, $100 \mu \mathrm{g} / \mathrm{mL}$ streptomycin, $10 \%$ (v/v) heat-inactivated foetal calf serum and $1 \%(\mathrm{v} / \mathrm{v})$ human urine. The parasites were harvested in the log-phase of growth; they were washed three times with phosphate-buffered saline (PBS), $\mathrm{pH} 7.2$ at $4^{\mathrm{O}} \mathrm{C}$ by centrifugation at $1.700 \mathrm{x}$ for $10 \mathrm{~min}$ each time. The final pellets were lyophilized and kept at $4^{\circ} \mathrm{C}$ until being used.

The pellets were resuspended in 200 volumes of $0.15 \mathrm{M}$ $\mathrm{NaOH}$ containing $0.014 \mathrm{M}$ PMSF (Sigma) followed by three cycles of sonication at $40 \mathrm{~Hz}$ for $20 \mathrm{~s}$ each time in an ice bath [11]. The suspension was slowly shaken $(150 \mathrm{rpm})$ for $6 \mathrm{~h}$ at $4^{\mathrm{O}} \mathrm{C}$. The $\mathrm{pH}$ was adjusted to 7.2 , and the material kept under slow shaking overnight. The extract was centrifuged at 10,000 $\mathrm{x} g$ for $20 \mathrm{~min}$ at $4^{\circ} \mathrm{C}$. The supernatant was collected, and the protein concentration measured by protein assay (Bio-Rad) and stored at $-20^{\circ} \mathrm{C}$.

\section{Enzyme Immunoassay (EIA)}

EIA was carried out in flat-bottom 96-well microtiter plates (Falcon). The plates were coated with $10 \mu \mathrm{g}$ of antigen $/ \mathrm{mL}$ $(100 \mu \mathrm{L} /$ well) in coating buffer $(0.1 \mathrm{M}$ carbonate-bicarbonate buffer, $\mathrm{pH}$ 9.6) and incubated overnight at $4^{\mathrm{O}} \mathrm{C}$. After being blocked by albumin buffer ( $1 \%$ bovine albumin in PBS) for $2 \mathrm{~h}$ at room temperature, the wells were loaded with $100 \mu \mathrm{L}$ serum ( $1: 150$ dilution in albumin buffer) and incubated at $25^{\circ} \mathrm{C}$ for $2 \mathrm{~h}$. The plates were washed three times with PBS and incubated in $100 \mu \mathrm{L}$ anti-human IgG-peroxidase conjugate
(Sigma) $\left(1: 5,000\right.$ dilution in albumin buffer) at $25^{\circ} \mathrm{C}$ for $2 \mathrm{~h}$. After being washed three times, the plates were incubated in $100 \mu \mathrm{L}$ of $1 \mathrm{mg} / \mathrm{mL}$ OPD (o-phenylenediamine dihydrochloride, Sigma) in $0.05 \mathrm{M}$ citrate-phosphate buffer, $\mathrm{pH} 5.0$ for $15 \mathrm{~min}$ at room temperature. The reaction was stopped by $50 \mu \mathrm{L}$ of $3 \mathrm{M}$ $\mathrm{H}_{2} \mathrm{SO}_{4}$, and the optical density was measured at $492 \mathrm{~nm}$ in Anthos 2010 microplates reader (Labtec). Each sample was assayed in triplicate.

Antibody levels were expressed as optical density. The cutoff point was set as the mean plus 2 standard deviations of values of the healthy controls to obtain maximum sensitivity and specificity. The cutoff point for anti-L. braziliensis IgG was 0.68 .

\section{Statistical Analysis}

The mean OD values of sera groups were compared by Student " $\mathrm{t}$ " test at a confidence level of $95 \%$ using Excel software. A probability value (p) $<0.05$ was considered statistically significant. Standard diagnostic indexes such as sensitivity, specificity, and positive and negative predictive values were calculated by using previously described formulas [19].

\section{Results}

Serum samples from $72 \mathrm{CL}$ and 151 non-ACL patients were tested for IgG-EIA (Figure 1). As shown in Table 1, a strong separation between cutaneous leishmaniasis and healthy controls, paracoccidioidomycosis and other disease controls was possible $(\mathrm{p}<0.0001)$. On the other hand, the mean optical absorbance of Chagas' disease patients group was higher than cutaneous leishmaniasis patients, and it was not possible to be distinguished.

Table 2 shows the diagnostic performance indexes of the test. The sensitivity was $93.0 \%$ (67/72 ACL patient samples), and the specificity was $94.8 \%$ in healthy controls ( $2 / 38$ healthy controls). In the other-diseases category, false positives were detected in toxoplasmosis (2/36 patients), and in recent toxoplasmosis (1/15 patients). The assay showed poor specificity in Chagas' disease (34/36 patients), and in paracoccidioidomycosis (11/12 patients). In this way the positive and negative predictive values were 57.3 and 95.3, respectively.

Serum samples from 85 suspicious ACL patients were tested for IgG-EIA. Table 3 summarizes the results in 76 patients with cutaneous ulcers. The IgG-EIA was positive in 28 out of 29 patients with positive search of Leishmania sp. (97.0\%). Of the 29 patients with cutaneous ulcers, but with both Leishmania sp. search and Montenegro's skin test negative, the IgG-EIA was negative in 28 (97.0\%), showing that the probable agent that caused the lesion, was not this parasite. Of 11 patients with positive Montenegro's skin test and negative search of parasite, the EIA was positive in $6(55.0 \%)$. The EIA was positive in 1 out of $4(25.0 \%)$ patients with negative search for the parasite, and it was negative in 3 patients with negative Montenegro's skin test. 
Table 1. Enzyme immunoassay with sera from American cutaneous leishmaniasis patients, healthy controls, and other disease controls

\begin{tabular}{lccc}
\hline Sera (n' ${ }^{\mathbf{0}}$ Tested) & Mean OD \pm SD & 95\% Confidence intervals & $\begin{array}{c}\text { p (ACL vs. other } \\
\text { sera groups) }\end{array}$ \\
\hline American cutaneous leishmaniasis (72) & $1.216 \pm 0.402$ & $1.120-1.311$ \\
Healthy controls (38) & $0.441 \pm 0.116$ & $0.403-0.480$ & $<0.0001$ \\
Other diseases controls (65) & & & $<0.0001$ \\
(non Chagas' disease or paracoccidioidomycosis) & $0.354 \pm 0.253$ & $0.291-0.417$ & $=0.097$ \\
Chagas' disease (36) & $1.353 \pm 0.400$ & $1.218-1.489$ & $=0.001$ \\
Paracoccidioidomycosis (12) & $0.814 \pm 0.139$ & $0.725-0.902$ & \\
\hline
\end{tabular}

Table 2. Diagnostic performance indexes of the enzyme immunoassay for the serological diagnosis of American cutaneous leishmaniasis

\begin{tabular}{|c|c|c|c|}
\hline \multirow{2}{*}{ Sera } & \multirow{2}{*}{ Sensitivity ${ }^{\mathbf{a}}$ Specificity ${ }^{\mathbf{b}}$} & \multicolumn{2}{|c|}{ Predictive value } \\
\hline & & Positive & Negative \\
\hline American cutaneous leishmaniasis & $67 / 72(93.0)$ & 57.3 & 95.3 \\
\hline Healthy controls & 36/38 (94.8) & & \\
\hline Other diseases controls & & & \\
\hline (non Chagas' disease or paracoccidioidomycosis) & $62 / 65(95.4)$ & & \\
\hline Chagas' disease & $2 / 36(5.5)$ & & \\
\hline Paracoccidioidomycosis & $1 / 12(8.3)$ & & \\
\hline
\end{tabular}

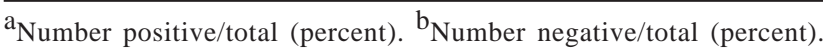

Table 3. Comparison of enzyme immunoassay (EIA), search of Leishmania sp. and Montenegro's skin test (MST) in 76 patients with cutaneous ulcers suspicious of American cutaneous leishmaniasis

\begin{tabular}{|c|c|c|c|c|}
\hline \multirow{2}{*}{\multicolumn{2}{|c|}{$\begin{array}{l}\text { Search of } \\
\text { Leishmania sp.MST }\end{array}$}} & \multicolumn{2}{|c|}{ EIA } & \multirow[b]{2}{*}{ Total } \\
\hline & & Positive & Negative & \\
\hline \multirow[t]{3}{*}{ Positive } & Positive & 26 & & \\
\hline & Negative & 1 & & 29 \\
\hline & ND & 1 & 1 & \\
\hline \multirow[t]{3}{*}{ Negative } & Positive & 6 & 5 & \\
\hline & Negative & 1 & 28 & 44 \\
\hline & ND & 1 & 3 & \\
\hline \multirow[t]{3}{*}{ ND } & Positive & & & \\
\hline & Negative & & 3 & 3 \\
\hline & ND & & & \\
\hline \multicolumn{2}{|l|}{ Total } & 36 & 40 & 76 \\
\hline
\end{tabular}

$\mathrm{ND}=$ not done.

All the 9 patients with mucous lesions, positive Montenegro's skin test and previous history of cutaneous ulcers, had a positive IgG-EIA, including two patients that did not have anti-L. braziliensis IgG detected by IIF.

\section{Discussion}

Cutaneous leishmaniasis is endemic in several tropical and subtropical countries worldwide, mostly affecting populations that reside in rural areas. ACL occurs in all of Brazilian states, and it is an endemic disease in Paraná State.
The more often employed standard methods to diagnose leishmaniasis are both MST and smear preparations. However, each one of these traditional methods has several limitations. The MST can not distinguish between actual or past infection $[9,10]$. Detection of parasites in smear preparations is the most conclusive in the diagnosis of ACL. However, parasitological diagnosis is invasive and often not sensitive. The possibility of parasite detection decreases with the increase of the time of lesion evolution [9]. The serology can be useful to the CL diagnosis in patients with no recent lesions as well as in patients with mucous ulcers. In these cases, where the number of parasite is low, it is difficult to demonstrate the parasite in lesions.

The results presented here demonstrate that EIA had a good performance. One of the problems of serological assays for ACL is the existence of cross-reactions with other diseases, including visceral leishmaniasis and Chagas' disease. In this study, it was possible to distinguish the group of cutaneous leishmaniasis and healthy controls or other disease controls, but a significant number of cross-reactions with Chagas' disease and paracoccidioidomycosis were observed in the test standardization. When the sera of Chagas' disease and paracoccidioidomycosis were excluded from the specificity analysis, it rised to $96 \%$. Serological cross-reactivity between leishmaniasis and Chagas' disease has been described by several authors $[9,16]$. Reports of cross-reactivity among cutaneous leishmaniasis and paracoccidioidomycosis for IgA antibodies were referred by Guimarães et al. [13]. The knowledge of this fact is very relevant, mainly in areas where the two 
Figure 1. Detection of anti-L. braziliensis IgG in sera of American cutaneous leishmaniasis (ACL) patients, healthy individuals, and controls with various diseases by enzyme immunoassay. Each symbol $(\bullet)$ stands for a single serum sample. The horizontal dotted line represents the cutoff value: 0.68 . The horizontal solid lines represent the mean optical density of the serum groups. $\mathrm{HC}=$ healthy controls; $\mathrm{TO}=$ toxoplasmosis; $\mathrm{RT}=$ recent toxoplasmosis; $\mathrm{CD}=\mathrm{Chagas}$ ' disease; $\mathrm{PM}=$ paracoccidioidomycosis; SI=syphilis; $n=$ number of samples.

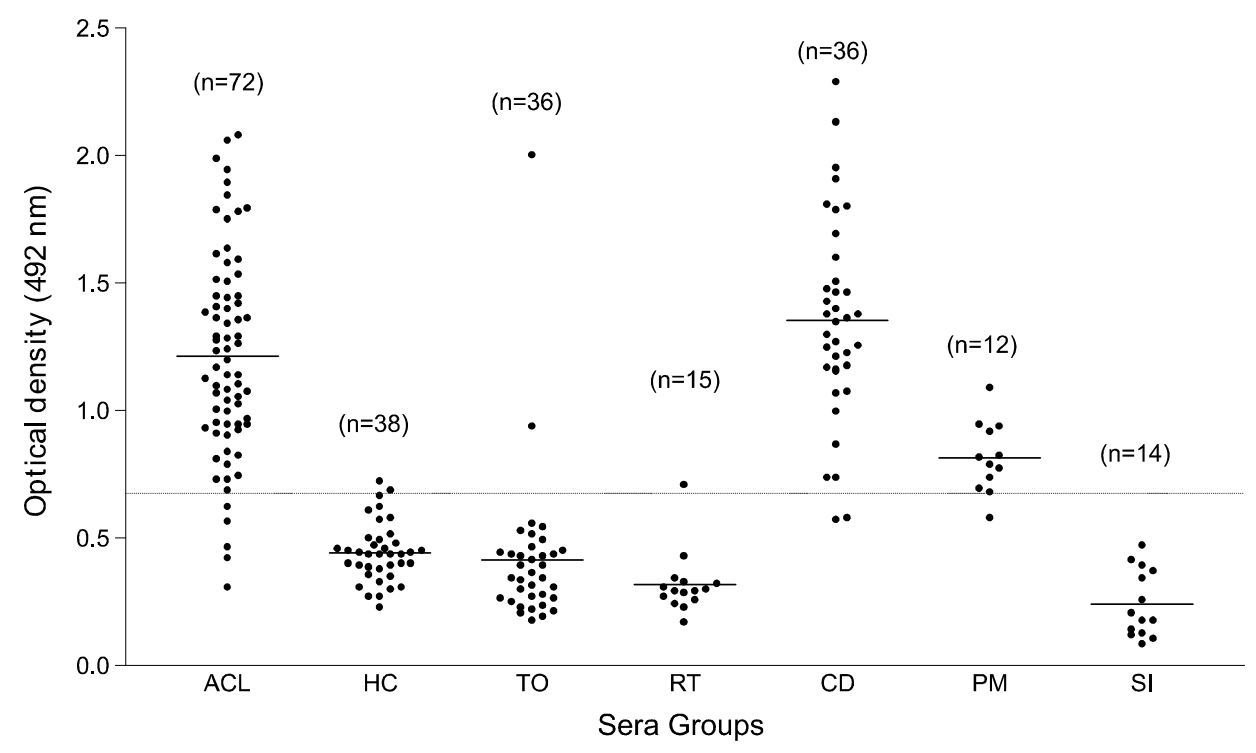

diseases are endemic, because cutaneous leishmaniasis and paracoccidioidomycosis can manifest similar cutaneous lesions.

In spite of the detected cross-reactivity, when IgG-EIA was used for diagnosis in patients with cutaneous ulcers suspicious of ACL, the test detected $97.0 \%$ of positive parasitological search, and it was negative in $97.0 \%$ of the patients that had both parasitological search and the Montenegro's skin test negatives. Gontijo and Carvalho [9] reported a sensitivity of approximately $92 \%$ by EIA, and suggested that this approach might have a potential for individual and epidemiological diagnosis in endemic regions. Although the results obtained by EIA have been coincident with those obtained by IIF for the patients with cutaneous lesions (data not shown), EIA showed great usefulness for diagnosis of patients with mucous lesion. In spite of the small number of patients with the mucous form of the disease tested, those patients that did not have antibodies detected by IIF presented positive EIA. Another advantage of the EIA is the absence of subjectivity in the reactions reading, which is a limiting factor of the IIF.

To sum up, the results shown here demonstrated that EIA presents good sensitivity and it may become an important tool for diagnosis and epidemiological studies of ACL endemic areas. Studies are being directed towards evaluating the use of EIA for analysis of the antibody levels of patients with CL before and after treatment.

\section{Acknowledgements}

The authors wish to thank Ms. Marina Marlede Gobbi and Ms. Ivone Alves for their technical assistance. The work was supported by Fundação Araucária and the Teaching and Research in Clinical Analysis Laboratory of the State University of Maringá.

\section{References}

1. Modabber F. Leishmaniasis. In: Tropical Disease Research: progress 1991-92: eleventh programme report of the UNDP/WHO Special Programme for Research and Training in Tropical diseases (TDR), WHO, Geneva, 1993:77-91.

2. Berman J.D. Human leishmaniasis: clinical, diagnostic, and chemotherapeutic developments in the last 10 years. Clin Infect Dis $1997 ; 24,684-703$.

3. Silveira T.G.V., Teodoro U., Arraes S.M.A.A., et al. An autochthonous case of cutaneous leishmaniasis caused by Leishmania (Leishmania) amazonensis Lainson \& Shaw, 1972, from the north of Paraná State, Brazil. Mem Inst Oswaldo Cruz 1990;85:475-6.

4. Silveira T.G.V., Teodoro U., Lonardoni M.V.C., et al. Aspectos epidemiológicos de Leishmaniose Tegumentar em áreas endêmicas do Estado do Paraná, Brasil. Cad Saúde Públ 1996;12:141-7.

5. Silveira, T. G. V., Arraes, S. M. A. A., Bertolini, D. A., Teodoro, U., Lonardoni, M. V. C., Roberto, A. C. B. S., Ramos, M., Sobrinho, A. N., Ishikawa, E. and Shaw, J.. Observações sobre o diagnóstico laboratorial e a epidemiologia da leishmaniose tegumentar no Estado do Paraná, sul do Brasil. Rev Soc Bras Med Tropical 1999;32:413-23.

6. Lima A.P., Minelli L., Teodoro U., Comunello E. Distribuição da leishmaniose tegumentar por imagens de sensoriamento remoto orbital, no Estado do Paraná, Brasil. An Bras Dermatol 2002;77:681-92.

7. Lonardoni M.V.C., Teodoro U., Arraes S.M.A.A., et al. Nota sobre leishmaniose canina no noroeste do Estado do Paraná, sul do Brasil. Rev. Saúde Pública 1993;27,378-9.

8. Luz E., Membrive N., Castro E.A., et al. Lutzomyia whitmani (Díptera: Psychodidae) as vector of Leishmania (V.) braziliensis in Paraná State, southern Brazil. Ann Trop Med Parasitol 2000;94:623-31. 
9. Gontijo B., Carvalho M.L.B. Leishmaniose tegumentar americana. Rev Soc Bras Med Trop 2003;36:71-80.

10. Vega-López F. Diagnosis of cutaneous leishmaniasis. Curr Opin Infect Dis 2003;16:97-101.

11. Guimarães M.C.S., Celeste B.J., Castilho E.A., et al. Imunoenzymatic assay (ELISA) in mucocutaneous leishmaniasis, Kala-azar, and Chagas' disease: an epimastigote Trypanosoma cruzi antigen able to distinguish between anti-Trypanosoma and anti-Leishmania antibodies. Am J Trop Med Hyg 1981;30,942-7.

12. Guimarães M.C.S., Celeste B.J., Camargo M.E., Diniz J.M.P. Seroepidemiology of cutaneous leishmaniasis from Ribeira do Iguape Valley, IgM and IgG antibodies detected by means of an immunoenzymatic assauy (ELISA). Rev Inst Med Trop São Paulo 1983;25:108-12.

13. Guimarães M.C.S., Ferreira A.W., Carvalho M.B. de, et al. AntiLeishmania IgA imunoenzimatic assay in mucocutaneous leishmaniasis. Rev Inst Med Trop São Paulo 1984;26:353-6.

14. Guimarães M.C.S., Celeste B.J., Franco E.L. Evaluation of dot enzyme-linked immunosorbent assay for mucocutaneous leishmaniasis and comparison with microplate enzyme immunoassay. J Clin Microbiol 1986;24:364-7.
15. Roffi J., Dedet J.-P., Desjeux P., Garré M.-T. Detection of circulating antibodies in cutaneous leishmaniaisi by enzymelinked immunosorbent assay (Elisa). Am J Trop Med Hyg 1980;29:183-9.

16. Anthony R., Christensen H.A., Johnson C.M. Micro enzymelinked immunosorbent assay (Elisa) for the serodiagnosis of New World leishmaniasis. Am J Trop Med Hyg $1980 ; 29: 190-4$.

17. Celeste B.J., Guimarães M.C.S., Souza J.M.P. de, Bergamaschi D.P. Reproducibility of alkaline antigens of Leishmania major-like and Leishmania (V.) braziliensis evaluated by IgG-ELISA. Comparison of antigens added of protein inhibitor (PMSF) or not. Rev Inst Med Trop São Paulo 1998; 40:287-90.

18. Masuda A., Nascimento S.F., Guerra C.S., et al. Analysis of the specificity of human antibodies to antigens of Leishmania braziliensis braziliensis. Rev Inst Med Trop São Paulo 1989;31:228-34.

19. Griner P.F., Mayewski R.J., Mushlin A.I., Greeland P. Selection and interpretation of diagnostic tests and procedures. Ann Int Med 1981;94,562-3. 